\title{
PESQUISA NACIONAL SOBRE CONDUTAS NA PANCREATITE AGUDA
}

\author{
A BRAZILIAN SURVEY REGARDING THE MANAGEMENT OF ACUTE PANCREATITIS
}

\author{
Tércio De Campos, TCBC-SP'; José Gustavo Parreira, TCBC-SP'; \\ Edivaldo Utiyama, TCBC-SP'; Samir Rasslan, TCBC-SP ${ }^{4}$
}

\begin{abstract}
RESUMO: Objetivo: Avaliar como a pancreatite aguda é vista e tratada pelo cirurgião brasileiro. Método: Trata-se de um questionário prospectivo enviado aos membros do Colégio Brasileiro de Cirurgiões (CBC). Dois mil questionários foram enviados obtendo-se 618 respostas $(30,9 \%)$. O questionário constituía de perguntas relacionadas à experiência do cirurgião e ao tratamento da PA. Resultados: Cento e oitente e dois entrevistados (33,6\%) disseram tratar até cinco casos por ano e $147(27,2 \%)$ tratam de seis a 10 casos por ano. Dentre os critérios utilizados para a definição de PA, o mais citado foi a avaliação clínica por 306 (57,4\%) entrevistados, seguido dos critérios de Ranson por 294 (55,2\%) e TC por $262(49,2 \%)$. Com relação ao uso da TC, 275 (51,5\%) entrevistados responderam que realizam a TC em todos os doentes com PA. O suporte nutricional parenteral foi o método de escolha indicado por $248(46,6 \%)$ entrevistados. A infecção da coleção e/ou necrose pancreática é a principal indicação operatória com 447 $(83,6 \%)$ respostas. O melhor período para operar um doente com PA grave foi considerado até quatorze dias por $278(54,2 \%)$ entrevistados. Com relação aos antibióticos, $371(68,6 \%)$ entrevistados disseram que utilizam antibióticos no tratamento da PA grave. Conclusão: Estes resultados demonstram uma ampla variação no tratamento da PA no Brasil. A pouca experiência dos cirurgiões e os temas controversos são os fatores principais responsável para esta falta de padronização. A realização de um Consenso nacional baseado nos novos conceitos e na experiência mundial é crucial para ajustar estas condutas (Rev. Col. Bras. Cir. 2008; 35(5): 304-310).
\end{abstract}

Descritores: Pancreatite/terapia; Doença aguda; Pesquisa; Consenso; Condutas na prática dos médicos.

\section{INTRODUÇÃO}

A pancreatite aguda (PA) é uma doença freqüente, com incidência que varia de 50 a 80 casos por ano para cada 100.000 habitantes nos Estados Unidos ${ }^{1,2}$. No Brasil a incidência é de 15,9 casos por ano para cada 100.000 habitantes, segundo dados de 2006 do DATASUS e IBGE ${ }^{3,4}$.

A forma grave da PA está presente, na forma como é definida atualmente, em até $25 \%$ dos casos com mortalidade de 10 a $20 \%$ neste subgrupo $2,5,6$.

$\mathrm{O}$ tratamento da pancreatite aguda permanece controverso em vários tópicos, devido principalmente à dificuldade da realização de estudos clínicos randomizados prospectivos, dado o pequeno número de casos graves em cada centro. Segundo o DATASUS, em 2006 foram registrados 1999 casos de PA na cidade de São Paulo, provenientes de 201 centros com capacidade de internação, com média de 2,5 casos graves por estabelecimento por ano, demonstrando a dificuldade da concretização destes estudos ${ }^{3}$.

$\mathrm{O}$ estudo ou a avaliação de doentes com PA freqüentemente é complexo, pois trata-se de uma doença de etiologia, forma de apresentação clínica, aspecto anatomo- patológico e tratamento distintos. Por isso existe uma grande divergência de resultados quando se analisam os trabalhos realizados. Sendo assim, existem vários Consensos na literatura médica que direcionam as condutas na pancreatite agu$\mathrm{da}^{1,2,5,7,8}$. Porém, algumas vezes as orientações destes Consensos não são claras em situações controversas, tais como o uso de antibióticos e a indicação da papilotomia endoscópica, gerando mais dúvidas para o cirurgião que trata estes doentes.

Uma pesquisa realizada previamente na comunidade européia com especialistas em doenças do fígado, vias biliares e pâncreas identificou uma série de dificuldades na padronização de condutas na PA, com alguns pontos de consenso e várias situações de discordância? .

Baseado nestas dificuldades, idealizou-se esta pesquisa com o objetivo de avaliar como a pancreatite aguda é vista e tratada pelo cirurgião brasileiro.

\section{MÉTODO}

Trata-se de um questionário prospectivo realizado com o auxílio da ferramenta Survey Monkey

1. Doutor; Médico Assistente da Clínica Cirúrgica III da Faculdade de Medicina da Universidade de São Paulo; Professor Assistente do Grupo de Vias Biliares e Pâncreas do Departamento de Cirurgia da Faculdade de Ciências Médicas da Santa Casa de São Paulo e Chefe de Equipe do Serviço de Emergência da Faculdade de Ciências Médicas da Santa Casa de São Paulo.

2. Doutor; Médico Assistente da Clínica Cirúrgica III da Faculdade de Medicina da Universidade de São Paulo; Professor Assistente e Chefe de Equipe do Serviço de Emergência da Faculdade de Ciências Médicas da Santa Casa de São Paulo.3. Professor Doutor do Departamento de Cirurgia da Faculdade de Medicina da Universidade de São Paulo. 4. Livre-Docente; Professor Titular de Cirurgia Geral da Faculdade de Medicina da Universidade de São Paulo

Recebido em 14/03/2008

Aceito para publicação em 15/06/2008

Conflito de interesses: nenhum

Fonte de financiamento: nenhuma

Trabalho realizado no Laboratório de Investigação Médica 62 da Faculdade de Medicina da Universidade de São Paulo. 
http://www.surveymonkey.com) e enviado pela Internet aos membros do Colégio Brasileiro de Cirurgiões (CBC) que tinham endereço eletrônico no cadastro do CBC. Foram enviados efetivamente 2.020 questionários, pois muitos e-mails estavam desatualizados e retornaram. Devido a problemas técnicos na abertura da pesquisa por alguns membros do CBC, estes questionários foram re-enviados, obtendo-se 618 respostas $(30,6 \%)$ num período de dois meses em que o questionário permaneceu aberto.

O questionário constituía-se de três partes: a primeira relacionada a informações profissionais dos entrevistados, tais como especialidade, tipo de hospital e cidade onde trabalha, tempo de formado e se atende doentes com PA. Caso o entrevistado respondesse que não atende doentes com PA a entrevista era encerrada. Em caso de resposta afirmativa para esta última pergunta a pesquisa prosseguia para a segunda fase, onde eram colocadas questões relacionadas à experiência do cirurgião no tratamento da PA, como o número de casos atendidos por ano, e perguntas relacionadas especificamente ao tratamento, tais como definição de gravidade, emprego da Tomografia Computadorizada (TC) e da ColangioPancreatografia Retrógrada Endoscópica (CPRE), opções de suporte nutricional, definição da indicação operatória e uso de antibióticos. A terceira parte foi reservada apenas aos que responderam afirmativamente ao uso de antibióticos, relacionando indicação, tipo de antibióticos e tempo de utilização.

Dependendo da pergunta, as respostas aceitas poderiam ser únicas ou múltiplas, e apenas as últimas perguntas de cada parte eram de resposta obrigatória, pois estas definiriam se o entrevistado iria para a próxima fase ou se encerraria a pesquisa. A porcentagem de cada resposta era calculada baseada no número de respostas obtidas para cada pergunta, o que poderia gerar um número total diferente de respostas para cada pergunta, já que não existia a obrigatoriedade de todas as perguntas serem respondidas.

Os dados obtidos foram automaticamente transferidos para uma planilha de Excel, onde foram computados.

\section{RESULTADOS}

\section{Informações profissionais}

Com relação às informações profissionais, 350 entrevistados $(58,3 \%)$ responderam que sua principal especialidade é a Cirurgia Geral, $166(27,7 \%)$ a Cirurgia do Aparelho Digestivo, sete Gastroenterologia (1,2\%), 12 Emergência (2\%), 65 outra especialidade $(10,8 \%)$ e 18 não responderam $(2,9 \%)$.

O principal local de trabalho dos entrevistados é o Hospital Público (47,1\%), seguido de Hospital Privado (32,8\%), Faculdade $(9,1 \%)$ e Consultório particular $(7 \%)$. As cidades dos entrevistados estão apresentadas na figura 1, sendo que de São Paulo e Rio de Janeiro vieram o maior número de respostas.

Com relação ao tempo de formado, $187(31,1 \%)$ são formados a menos de 10 anos, 148 (24,7\%) têm de 10 a 20 anos de formado, $155(25,8 \%)$ de 20 a 30 anos, $86(14,3 \%)$ têm de 30 a 40 anos, e 24 (4\%) entrevistados mais de 40 anos.

Dos 618 entrevistados, $582(94,2 \%)$ responderam que tratam doentes com PA, e apenas estes seguiram para as perguntas seguintes.

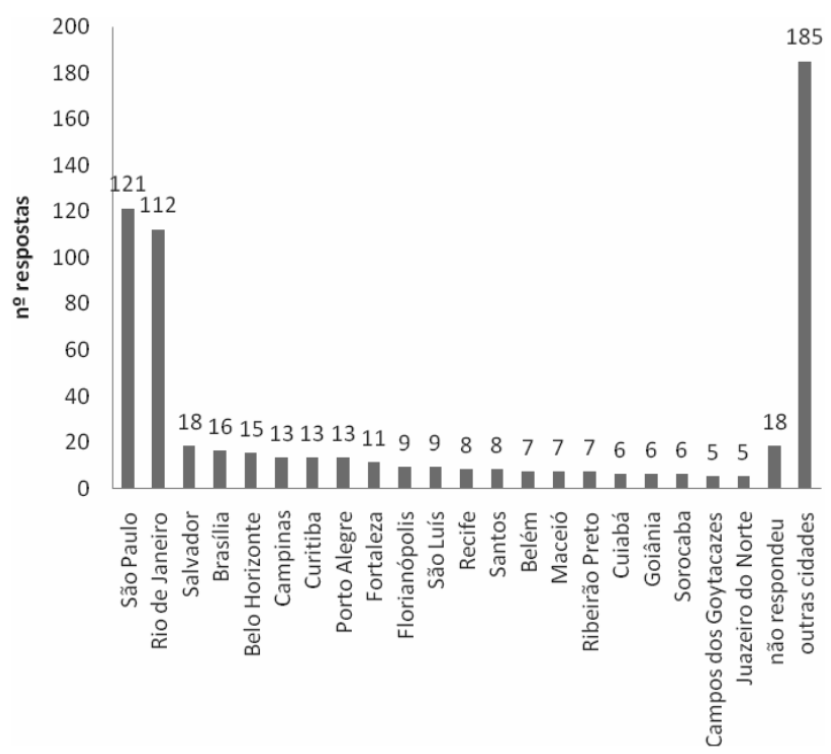

Figura 1 - Número de respostas relacionadas à cidade dos entrevistados.

\section{Tratamento da Pancreatite Aguda}

A primeira pergunta desta parte avalia o número de casos tratados pelos entrevistados, sendo que $182(33,6 \%)$ dos que responderam esta pergunta disseram tratar até cinco casos por ano, $147(27,2 \%)$ tratam de seis a 10 casos por ano, $111(20,5 \%)$ atendem de 11 a 20 casos por ano, $73(13,5 \%)$ cuidam de 21 a 50 casos por ano, enquanto que $28(5,2 \%)$ atendem mais de 50 doentes por ano.

Dentre os critérios utilizados para a definição de gravidade na pancreatite aguda, o mais citado foi a avaliação clínica por $306(57,4 \%)$ entrevistados, seguido dos critérios de Ranson por 294 (55,2\%), Tomografia por 262 (49,2\%), APACHE II por $167(31,3 \%)$ e proteína C reativa por $68(12,8 \%)$ entrevistados (Tabela 1).

Com relação ao uso da TC, 275 (51,5\%) entrevistados responderam que realizam a TC em todos os doentes com PA, enquanto que 235 (44\%) se orientam por critérios de gravidade para fazer a TC. O melhor período para realizar a TC foi de três a quatro dias após o início do surto para 253 entrevistados $(47,7 \%)$, na admissão para $179(33,8 \%)$, uma semana após o início do surto para 74 (14\%), e 10 dias após o início do surto para $24(4,5 \%)$.

A CPRE é indicada por $229(43,1 \%)$ dos entrevistados nos casos de PA com colangite, 157 (29,5\%) nos doentes com icterícia, $131(24,6 \%)$ em todos os doentes com PA de origem biliar, enquanto que $65(12,2 \%)$ entrevistados responderam que não tem este método disponível.

O suporte nutricional parenteral foi o método de escolha indicado por 248 (46,6\%) entrevistados (Figura 2).

A infecção da coleção e/ou necrose pancreática é a principal indicação operatória dentre as respostas obtidas, com $447(83,6 \%)$ respostas, seguido de piora clínica com 147 $(27,5 \%)$, presença de necrose com $61(11,4 \%)$ e presença de coleções com $57(10,7 \%)$ respostas.

O melhor período para operar um doente com PA grave está representado na figura 3. 
Tabela 1 - Métodos empregados para avaliação da gravidade da pancreatite aguda.

\begin{tabular}{lrc}
\hline Método & n $(\%)$ \\
\hline Avaliação clínica & $79(14,8)$ \\
Critérios de Ranson & $76(14,3)$ \\
Avaliação clínica + Ranson + TC & $57(10,7)$ \\
APACHE II & $39(7,3)$ \\
Avaliação clínica + TC & $38(7,1)$ \\
Critérios de Ranson + TC & $30 \quad(5,6)$ \\
Avaliação clínica + Ranson + APACHE II + TC & $26 \quad(4,9)$ \\
Avaliação clínica + Ranson & $25 \quad(4,7)$ \\
TC & $23 \quad(4,3)$ \\
Critérios de Ranson + APACHE II & $21 \quad(3,9)$ \\
Avaliação clínica + Ranson + APACHE II + TC + PCR & $19 \quad(3,6)$ \\
APACHE II + TC & $12 \quad(2,3)$ \\
Avaliação clínica + APACHE II + TC + PCR & $11 \quad(2,1)$ \\
Avaliação clínica + Ranson + TC + PCR & $9 \quad(1,7)$ \\
Avaliação clínica + APACHE II + TC & $9 \quad(1,7)$ \\
Outra combinação de métodos & $59(11,0)$ \\
\hline
\end{tabular}

$P C R=$ Proteína $C$ reativa, $T C=$ Tomografia Computadorizada .

A colecistectomia é indicada na mesma internação no doente com PA leve por 382 entrevistados $(71,5 \%)$, enquanto que $152(28,5 \%)$ indicam-na eletivamente.

Com relação aos antibióticos, $371(68,6 \%)$ entrevistados disseram que utilizam antibióticos no tratamento da PA grave, e seguiram para a fase seguinte da pesquisa, contra 170 $(31,4 \%)$ que responderam não utilizá-los.

\section{Emprego de antibióticos na pancreatite aguda}

Dentre os entrevistados que responderam utilizar antibióticos na PA, a principal indicação para o seu emprego

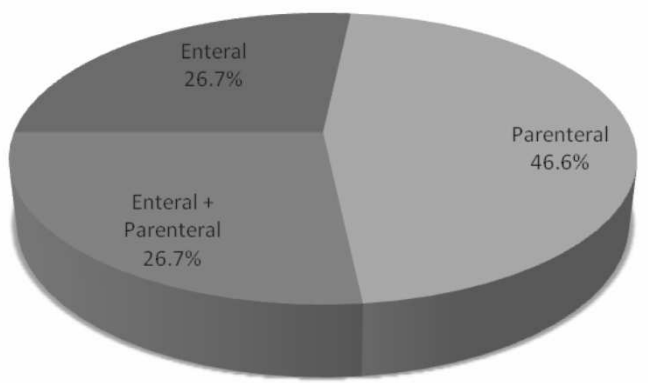

Figura 2 - Método de suporte nutricional de escolha na pancreatite aguda grave.

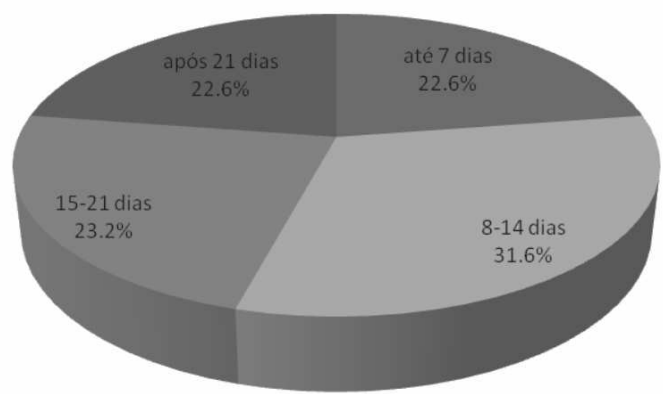

Figura 3 - Melhor momento para indicação cirúrgica na pancreatite aguda grave. foi a presença de necrose, apontada por $161(44,9 \%)$ entrevistados, seguido de presença de coleção por 114 (31,8\%). Cem entrevistados $(27,9 \%)$ responderam usar antibióticos em todos os doentes com PA, e $81(22,6 \%)$ afirmaram indicar antibióticos nos doentes tratados em Unidade de Terapia Intensiva. Critérios de Ranson maior que três e APACHE II maior que oito foram indicação para o uso de antibióticos para $72(20,1 \%)$ e $66(18,4 \%)$ dos entrevistados, respectivamente. A PCR maior que $150 \mathrm{mg} / \mathrm{l}$ foi indicação para o uso de antibióticos para 34 $(9,5 \%)$ entrevistados (figura 4$)$.

O antibiótico mais utilizado é o Imipenem com 155 respostas $(43,5 \%)$, seguido da associação do Ciprofloxacin e o Metronidazol com 60 respostas (16,9\%). Quarenta e um entrevistados $(11,5 \%)$ responderam usar o Ceftriaxone, $27(7,6 \%)$ utilizam o Ceftriaxone associado ao Metronidazol, 27 responderam que usam o Ciprofloxacin $(7,6 \%)$ isoladamente, e 46 $(12,9 \%)$ utilizam outros esquemas de antibióticos.

Com relação ao período de utilização dos antibióticos, 25 entrevistados (7\%) responderam que usam por um período até sete dias, enquanto que $81(22,6 \%)$ usam de oito a 10 dias, $159(44,4 \%)$ responderam de 10 a 14 dias e $80(22,4 \%)$ de 15 a 21 dias. Treze entrevistados $(3,6 \%)$ responderam outros períodos.

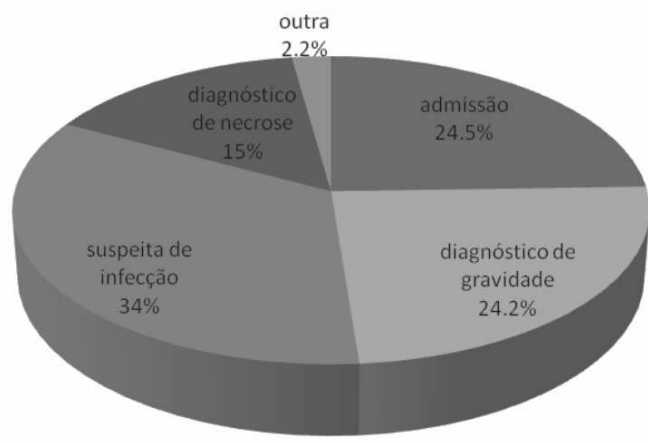

Figura 4 - Momento do início do uso de antibióticos na pancreatite aguda. 


\section{DISCUSSÃo}

Uma pesquisa sobre a PAé algo inédito no Brasil, mas não no mundo. King \& Siriwardena realizaram uma pesquisa na Europa em 1999 com os membros do capítulo europeu da International Hepato-Pancreato-Biliary Association, onde 866 questionários foram enviados e 329 respostas foram obtidas $(38 \%)^{9}$. Em números relativos obtivemos resultados semelhantes, com 618 respostas $(30,6 \%)$, porém considerando números absolutos obtivemos mais respostas devido ao grande número de cirurgiões membros do CBC. Existe uma diferença entre as duas pesquisas, pois a européia avaliou a resposta apenas de especialistas em doenças do fígado, vias biliares e pâncreas, enquanto que esta pesquisa aqui apresentada avalia respostas dos membros do CBC, ou seja, do cirurgião geral, como se autointitulam 350 entrevistados $(58,3 \%)$ e do cirurgião do aparelho digestivo em 166 respostas $(27,7 \%)$. Nenhum dos entrevistados se auto-intitulou especialista em pâncreas.

Deve-se ter cuidado ao analisar os resultados desta pesquisa, porque alguns tipos de viés são esperados, tais como, o fato desta pesquisa abordar uma população específica composta por membros da maior sociedade cirúrgica do país, que pode não traduzir exatamente o pensamento dos cirurgiões não filiados, e a formulação das perguntas pode não ter sido interpretada da mesma forma por todos os entrevistados. Como fatores positivos desta pesquisa nacional sobre a européia têmse o fato de ter sido realizada em apenas um país, eliminando problemas como a tradução da pesquisa para diversas línguas e a heterogeneidade da população dos diferentes países.

A distribuição das respostas da pesquisa segundo a cidade de trabalho mostra uma maior concentração das respostas no eixo Rio-São Paulo, devido ao maior número de cirurgiões nestas cidades, apesar de que foram obtidas respostas de todas as partes do país.

Alguns dados epidemiológicos obtidos na pesquisa são particularmente interessantes, porque traçam um perfil do novo cirurgião. Quase metade dos entrevistados disse trabalhar principalmente em hospital público, e menos de $10 \%$ têm sua principal atividade em alguma faculdade. Outro dado interessante relacionado à experiência do cirurgião que respondeu o questionário, é que cerca de um terço dos entrevistados tem menos de 10 anos de formado, e mais da metade têm menos de 20 anos de formado, demonstrando um perfil jovem e preocupado em responder à pesquisa.

A parte da pesquisa que trata sobre as condutas na PA começa mostrando um dado muito interessante, no que diz respeito ao número de casos atendidos por cada médico por ano, onde se observa que $60,8 \%$ dos entrevistados atende menos de um caso de PA por mês, mostrando esta ser uma doença pouco freqüente para o cirurgião. Considerando que $25 \%$ dos casos são definidos como graves, a maioria dos cirurgiões atende menos de dois casos graves por ano, o que faz com que a PA grave, devido às suas várias formas de apresentação, seja um desafio para o cirurgião pouco experiente e pouco habituado com esta doença. Este resultado difere dos obtidos pela pesquisa européia, onde $26,4 \%$ atendem menos de um caso por mês, e $34 \%$ dos entrevistados atendem mais de 20 casos por ano, contra 18,7\% nesta amostra ${ }^{9}$. Esta dife- rença se justifica pelo perfil da população européia entrevistada, mais voltada para as afecções bilio-pancreáticas.

Uma grande discussão na literatura atualmente é como definir a gravidade da PA. Segundo a classificação de Atlanta, que é utilizada atualmente, a PA pode ser dividida em forma leve ou grave dependendo do desenvolvimento de disfunção orgânica e/ou complicações locais ${ }^{5}$. A forma leve corresponde à maioria dos casos, com resolução espontânea em poucos dias, sem necessidade de tratamento específico. A forma grave da PA é definida pela presença de um ou mais dos seguintes critérios: escore de Ranson $=3$ ou APACHE II = 8; falência de um ou mais sistemas, tais como choque, insuficiência respiratória, falência renal, sangramento gastrointestinal, trombocitopenia e hipocalemia grave; e complicações locais tais como necrose pancreática, abscesso e pseudocisto de pâncreas ${ }^{5}$. A identificação precoce destes doentes graves permite o tratamento intensivo adequado, possibilitando a redução da disfunção orgânica e conseqüente diminuição da mortalidade. Os dois métodos mais difundidos na avaliação da falência orgânica na PA são os critérios de Ranson ${ }^{10}$ e o APACHE II ${ }^{11}$. A determinação inicial da necrose pancreática tem papel importante para a definição do risco de infecção na segunda fase da doença, e para a introdução de antibióticos precocemente nos doentes com necrose maior que $30 \%{ }^{12,13}$. Apesar de muitos avanços em métodos diagnósticos e consensos na literatura, nesta amostra, o principal critério para se definir a gravidade da PA foi a avaliação clínica com 14,8\% das respostas, seguido dos critérios de Ranson (14,3\%), avaliação clínica associada aos critérios de Ranson e à TC (10,7\%), APACHE II (7,3\%) e avaliação clínica associada a TC $(7,1 \%)$ (Tabela 1$)$. Resultados semelhantes são observados na pesquisa européia, onde os critérios de Ranson se encontram em primeiro lugar (10\%), seguido de avaliação clínica associada ao APACHE II (8\%), avaliação clínica associada à PCR $(8 \%)$ e somente avaliação clínica $(6 \%)^{9}$. Métodos utilizados 30 anos atrás, tais como a avaliação clínica e os critérios de Ranson, continuam sendo os preferidos na determinação da gravidade na PA.

Com relação ao emprego de métodos de imagem, mais da metade dos entrevistados fazem TC em todos os doentes com PA. O melhor período para a realização da TC é o período de três a quatro dias após o início do surto para 47,7\% dos entrevistados. Cerca de um terço dos entrevistados realizam a TC na admissão destes doentes. Discutem-se os problemas relacionados à utilização de contraste na $\mathrm{PA}$, que poderia transformar uma PA leve em necrótica ${ }^{14}$. $\mathrm{O}$ fator custo também deve ser considerado, além do fato de que o principal fator local que influencia o prognóstico de um doente com PAé a necrose, que só pode ser vista na TC a partir do terceiro dia do início do surto e idealmente a partir do quinto dia ${ }^{15}$.

Na literatura não é bem definido quando deve ser realizada a CPRE no doente com $\mathrm{PA}^{16}$. A presença de colangite é uma situação de consenso, e também foi a principal indicação dos entrevistados. Porém, alguns trabalhos discutem se na PA biliar grave a CPRE deve ser realizada. Estes trabalhos não chegaram a um consenso sobre a indicação da CPRE na PA devido a resultados divergentes ${ }^{17,19}$. 
Contudo, não existe divergência de sua indicação nos casos de PA acompanhados de colangite ou nas situações de cálculo impactado na papila, demonstrado clinicamente por piora progressiva da icterícia. A dificuldade de disponibilidade da CPRE também deve ser considerada, pois mais de $10 \%$ dos entrevistados não têm esta possibilidade, e muitos dos que têm este método disponível, não o têm imediatamente caso necessário.

Outro aspecto de discussão é o uso de suporte nutricional. Tradicionalmente o conceito de que o pâncreas deveria ficar em repouso, ou seja, em jejum, foi amplamente difundido e seguido. Recentemente novos estudos mostraram benefícios da nutrição enteral através de sonda locada na primeira porção jejunal, com relação à redução da resposta inflamatória, redução da infecção e redução dos escores de gravidade $^{20}$. Os números desta pesquisa mostram que o método parenteral exclusivo ainda é o preferido por quase metade dos entrevistados. As dificuldades de alimentação enteral como distensão abdominal e intolerância nos primeiros dias são fatores desencorajadores para grande parte dos médicos, a despeito dos benefícios comprovados. Outro ponto a ser considerado são os riscos do suporte nutricional parenteral, como acidentes de punção e maior risco de infecção, além do custo mais elevado.

Com relação ao tratamento cirúrgico, a principal indicação dos entrevistados foi a presença de infecção da necrose ou das coleções $(83,6 \%)$, situação consagrada classicamente como a indicação de tratamento cirúrgico nestes doentes. A discordância surge no melhor período para operar estes doentes, onde $54,2 \%$ consideram que as primeiras duas semanas são as melhores para submeter estes doentes ao tratamento operatório. Na pesquisa européia $43 \%$ consideraram os primeiros 14 dias como os melhores. Isto ocorre principalmente devido à necessidade do cirurgião em querer fazer algo para um doente que esteja piorando clinicamente. E, como fatores complicadores existem os poucos casos que desenvolvem infecção neste período. Porém, poucos estudos prospectivos comparam operação precoce até 72 horas com operação após duas semanas, e todos mostrando vantagens para o tratamento operatório postergado ${ }^{21}$. A piora clínica do doente nas duas primeiras semanas da doença deve na maioria das vezes ser atribuída à resposta inflamatória sistêmica e à falência orgânica, apesar de que a possibilidade de infecção, especialmente naquele com necrose extensa, não pode ser descartada. Nesta situação, a punção com agulha fina guiada por TC pode ajudar o cirurgião a tomar uma decisão baseada principalmente na presença de bactéria na necrose pancreática ${ }^{7}$. A colecistectomia na mesma internação é o procedimento recomendado pelos consensos no doente com PA leve para evitar a recidiva da PA, e é também o procedimento de escolha pela grande maioria dos entrevistados $(70,4 \%)$. Na PA grave de origem biliar a maioria das recomendações orienta aguardar a recuperação total do surto para depois realizar a colecistectomia $^{22}$.

O emprego de antibióticos na PA talvez seja o tema de maior controvérsia no tratamento da PA. Vários estudos foram realizados nos últimos 15 anos, porém sem um resultado conclusivo ${ }^{15,23,24}$. Dois terços dos entrevistados responderam que utilizam antibióticos no tratamento da PA, e destes, a principal indicação é a presença de necrose (44,9\%). Porém, 27,9\% dos entrevistados utilizam antibióticos em todos os doentes com PA. Um terço inicia o esquema de antibióticos na suspeita de infecção, ou seja, na necessidade, conceito este defendido por Beger ${ }^{25}$, enquanto que o restante utiliza em outras situações, como na admissão dos doentes e na confirmação de PA grave. O uso de antibióticos na presença de necrose é o atual conceito defendido por aqueles que acreditam no benefício do uso precoce de antibióticos nos doentes com $\mathrm{PA}^{12,13}$. Os dois esquemas mais utilizados pelos entrevistados são aqueles descritos na literatura ${ }^{12}$, ou seja, o Imipenem $(43,5 \%)$ isoladamente, e o Ciprofloxacin associado ao Metronidazol(16,9\%), semelhantes ao da pesquisa européia, onde os Carbapenens foram escolhidos por $41 \%{ }^{9}$. Não existe nenhum estudo avaliando o tempo necessário para o uso de antibióticos, ou seja, as sugestões são baseadas em consensos, que recomendam em sua maioria o uso de 10 a 14 dias, e sua troca ou suspensão baseada em culturas e na evolução clínica do doente ${ }^{1,2,12}$. E, este foi o principal período relatado nas respostas obtidas nesta pesquisa.

A PA não é uma doença incomum, tanto que alguns cirurgiões têm a oportunidade de acompanhar vários casos ao longo de sua atividade, no entanto poucos são aqueles que acumulam uma experiência significativa no seu tratamento ${ }^{26}$.

Em resumo, a PA é uma doença complexa, tratada por jovens cirurgiões em sua maioria, pois os casos aparecem no Pronto-Socorro, com poucos casos graves vistos por ano por cada médico, associada a uma literatura plena de controvérsias e pontos discussão. As dificuldades da obtenção de informações num país de dimensões continentais como o Brasil acentua ainda mais o problema em situações como a PA.

Deste modo, baseado nestas dificuldades e nos resultados aqui obtidos, chega-se ao ponto onde um consenso nacional, atendendo às características e necessidades deste país, se faz necessário, para que se possa adequar às nossas possibilidades o melhor tipo de tratamento a estes doentes potencialmente graves.

\section{AGRADECIMENTOS}

A todos os membros do Colégio Brasileiro de Cirurgiões que destinaram parte de seu tempo para responder esta pesquisa, e sem os quais seria impossível a apresentação destes dados.À Sra. Maria de Fátima Pereira, Secretária do Colégio Brasileiro de Cirurgiões pelo empenho na divulgação desta pesquisa para os membros do Colégio. 


\begin{abstract}
Background: to evaluate as AP is managed by the Brazilian surgeon. Methods: A questionnaire has been sent to 2,000 members of the Brazilian College of Surgeons, with 618 (30.9\%) answers obtained. The questionnaire consisted of questions related to the experience of the surgeon and in particular to the treatment of AP. Results: One hundred and eighty-two interviewed (33.6\%) answered to treat up to five cases per year and $147(27.2 \%)$ treat six to ten cases per year. The most cited criteria used for the definition of severe AP was clinical evaluation for 306 (57.4\%) interviewed, followed by the Ranson criteria for $294(55.2 \%)$ and CT scan for 262 (49.2\%). Regarding the use of CT, 275 (51.5\%) interviewed answered that make use of CT scan for all patients with AP. The parenteral nutritional support was the method of choice indicated for 248 (46.6\%) interviewed. The infection of fluid collection and/or pancreatic necrosis was the main reason for surgical treatment with 447 (83.6\%) answers. The optimum period to operate a patient with severe AP was considered up to seven days for 278 (54.2\%) interviewed. With relation to antibiotics, 371 (68.6\%) said that they use antibiotics in the treatment of severe AP. Conclusion: These findings demonstrate a wide variation in the treatment of AP in Brazil. Little experience of the surgeons and controversial issues are the main factors responsible for this lack of standardization. A national Consensus based on new concepts and worldwide experience is crucial to adjust these thoughts.
\end{abstract}

Key words: Pancreatitis/therapy; Acute disease; Treatment; Consensus; Physician's practice patterns.

\section{REFERÊNCIAS}

1. Clancy TE, Benoit EP, Ashley SW. Current management of acute pancreatitis. J Gastrointest Surg. 2005; 9(3):440-52.

2. Toouli J, Brooke-Smith M, Bassi C, Carr-Locke D, Telford J, Freeny P, Imrie C, Tandon R. Guidelines for the management of acute pancreatitis. J Gastroenterol Hepatol. 2002;17 Suppl:S1539.

3. Brasil. Ministério da Saúde. DATASUS. (2007) Informações de saúde - 2006 [acesso em 2007 out 25]. Disponível em: http:// tabnet.datasus.gov.br/cgi/deftohtm.exe?sih/cnv/mrbr.def

4. Brasil. Instituto Brasileiro de Geografia e Estatístico-IBGE. Características gerais da população. Censo Demográfico 2000. [acesso em 2007 out 25] Disponível em: http://www.ibge.gov.br/home/ estatistica/populacao/censo2000/populacao/pop_Censo2000.pdf

5. Bradley EL III. A clinically based classification system for acute pancreatitis:Summary of the International Symposium on Acute Pancreatitis, Atlanta, Ga.,September 11 through 13, 1992. Arch Surg. 1993; 128(5):586-90.

6. Werner J, Hartwig W, Uhl W, Muller C, Buchler MW. Useful markers forpredicting severity and monitoring progression of acute pancreatitis. Pancreatology. 2003; 3(2):115-27.

7. Banks PA, Freeman ML; Practice Parameters Committee of the American College of Gastroenterology. Practice guidelines in acute pancreatitis. Am J Gastroenterol. 2006; 101(10):2379-400.

8. Working Party of the British Society of Gastroenterology; Association of Surgeons of Great Britain and Ireland; Pancreatic Society of Great Britain and Ireland; Association of Upper GI Surgeons of Great Britain and Ireland. UK guidelines for the management of acute pancreatitis. Gut. 2005; 54 Suppl 3:iii1-9.

9. King NK, Siriwardena AK. European survey of surgical strategies for the management of severe acute pancreatitis. Am J Gastroenterol. 2004; 99(4):719-28.

10. Ranson JH, Rifkind KM, Roses DF, Fink SD, Eng K, Localio SA. Objective early identification of severe acute pancreatitis. Am J Gastroenterol. 1974; 61(6):443-51.

11. Knaus WA, Draper EA, Wagner DP, Zimmerman JE. APACHE II: a severity of disease classification system. Crit Care Med. 1985; 13(10):818-29.

12. De Campos T, Assef JC, Rasslan S. Questions about the use of antibiotics in acute pancreatitis. World J Emerg Surg. 2006; 1:20.

13. Villatoro E, Bassi C, Larvin M. Antibiotic therapy for prophylaxis against infection of pancreatic necrosis in acute pancreatitis. Cochrane Database Syst Rev. 2006; 18(4):CD002941.
14. Apodaca-Torrez FR, Goldenberg A, Lobo EJ, Farah JFM, Triviño T, Montero EFS, et al. Evaluation of the effects of noniodinized and iodinized ionic contrast media and gadoteric acid in acute necrotizing pancreatitis: experimental study in rabbits. Pancreas. 2007; 35:e41-e44.

15. Werner J, Hartwig W, Buchler MW. Antibiotic prophylaxis: an ongoing controversy in the treatment of severe acute pancreatitis. Scand J Gastroenterol. 2007; 42(6):667-72.

16. Petrov MS. ERCP in acute biliary pancreatitis: the moor has done his duty, the moor may go. Am J Gastroenterol. 2007; 102(12):2859-60.

17. Neoptolemos JP, Carr-Locke DL, London NJ, Bailey IA, James D, Fossard DP. Controlled trial of urgent endoscopic retrograde cholangiopancreatography and endoscopic sphincterotomy versus conservative treatment for acute pancreatitis due to gallstones. Lancet. 1988; 2(8618):979-83.

18. Fan ST, Lai EC, Mok FP, Lo CM, Zheng SS, Wong J. Early treatment of acute biliary pancreatitis by endoscopic papillotomy. N Engl J Med. 1993; 328(4):228-32.

19. Folsch UR, Nitsche R, Ludtke R, Hilgers RA, Creutzfeldt W. Early ERCP and papillotomy compared with conservative treatment for acute biliary pancreatitis. The German Study Group on Acute Biliary Pancreatitis. N Engl J Med. 1997; 336(4):237-42.

20. McClave SA. Nutrition support in acute pancreatitis. Gastroenterol Clin North Am. 2007; 36(1):65-74.

21. Mier J, Leon EL, Castillo A, Robledo F, Blanco R. Early versus late necrosectomy in severe necrotizing pancreatitis. Am J Surg. 1997; 173(2):71-5.

22. Werner J, Feuerbach S, Uhl W, Buchler MW. Management of acute pancreatitis: from surgery to interventional intensive care. Gut. 2005; 54(3):426-36.

23. Dellinger EP, Tellado JM, Soto NE, Ashley SW, Barie PS, et al. Early antibiotic treatment for severe acute necrotizing pancreatitis: a randomized, double-blind, placebo-controlled study. Ann Surg. 2007;245(5):674-83.

24. Petrov MS. Meta-analyses on the prophylactic use of antibiotics in acute pancreatitis: many are called but few are chosen. Am J Gastroenterol. 2008; 103(7):1837-8; author reply 1838-9.

25. Beger HG, Rau B, Isenmann R, Schwarz M, Gansauge F, Poch B. Antibiotic prophylaxis in severe acute pancreatitis. Pancreatology. 2005; 5(1):10-9.

26. Dellinger EP. Pancreatic infection. In: Stein M, Marshal J, editors. A guide for the management of surgical infections. New York: Springer; 2002. p. 154. 
Como citar este artigo:

Campos T, Parreira JG, Utiyama E, Rasslan S. Pesquisa nacional sobre condutas na pancreatite aguda. Rev Col Bras Cir. [periódico na Internet] 2008; 35(5). Disponível em URL: http://www.scielo.br/ rcbc
Endereço para correspondência:

Tercio De Campos

Rua Desembargador Aragão, 62 - Vila Mariana

04102-010

São Paulo - SP

Tel.: (11) 3069-6555

HYPERLINK“mailto:tercio@uol.com.br”tercio@uol.com.br 